\title{
La difícil lectura del Antiguo Testamento hecha por el Concilio Vaticano II
}

Es un hecho el embarazo que produce en los cristianos la lectura del A.T. La mayoría no sabría responder por qué la Iglesia lo considera como sagrado y normativo. Es verdad que la Iglesia ha usado ampliamente el A.T.; aún hoy, la oración litúrgica en gran parte está formada por los salmos. Pero, precisamente es en este campo donde más se deja sentir el desafecto por el A.T. Y no es ciertamente de época reciente la costumbre de sustituir los salmos por otras oraciones en gran número de grupos o comunidades religiosas. Sería una ligereza pensar que este uso se hace por seguir una moda o por falta de conocimiento teológico. Sencillamente en muchos casos, el grupo religioso no se siente identificado con las preocupaciones de los salmistas. Pretender que el grupo se identifique con la espiritualidad de los salmos, sería una postura no lejana de aquellos fariseos del tiempo de Jesús que sometían el hombre al sábado.

Por otra parte, en las lecturas de la liturgia dominical se escoge una del A.T.; pero es evidente el carácter secundario que se le da. Esta lectura del A.T. siempre está en relación con el Evangelio del mismo día; así los predicadores no se sentirán atraídos a explicar el texto del A.T., cuando las mismas ideas se presentan en el N.T. de una manera más accesible y clara. Bajo este uso está la concepción de una historia de la salvación, que se extiende por el A.T., cuya culminación se quiere encontrar en el N.T., de tal manera que lo que se propone es una lectura cristiana del A.T., o, dicho de otro modo, que se encuentre a Cristo en el A.T. Tal pretensión, sin embargo, difícilmente se conjuga con el sentido crítico e histórico de hoy día, que evidentemente exige que los textos sean leídos e interpretados en la significación que el autor quiso plasmar con sus palabras. En todo texto hay una subjetividad depositada por el autor, $y$, al menos, por respeto a él, hay que intentar escuchar lo que él quiere decir. 
Cómo leer cristianamente el A.T. y, al mismo tiempo respetar el texto en su sentido histórico, he aquí un problema no resuelto.

A lo largo de la historia de la exégesis, las posiciones han girado en torno a estos dos polos: o bien la Iglesia se apropiaba el A.T., no respetando su alteridad, o bien acentuaba su carácter heterogéneo y en este caso no se sabía qué hacer con él. Es decir, o bien se afirmaba la continuidad entre el A.T. y el Nuevo, o bien se insistía en la ruptura. Éstas, evidentemente, son posturas extremas; caben posiciones intermedias. Incluso cabe la posibilidad de sostener la continuidad entre el A.T. y el Nuevo en algunos temas y afirmar la ruptura en otros al mismo tiempo.

El problema nace ya en los orígenes del cristianismo. El acontecimiento de Jesús impone una nueva lectura del A.T., que se elabora por diversos motivos. No faltan, desde luego, los motivos apologéticos: había que hacer creíble a Jesús en base a la Escritura admitida por los judíos. Pero había también otros motivos como los propiamente teológicos y pastorales: el A.T. ofrecía las únicas categorías posibles para entender la obra y la persona de Jesús. Precisamente la cristología se convierte en la clave de lectura que los cristianos hacen del A.T. De hecho todas las citas que el N.T. hace del Antiguo tienen un carácter más o menos cristológico ${ }^{1}$.

Una línea de pensamiento hablará del cumplimiento de las Escrituras del A.T. en el Nuevo. Se acentuará la continuidad entre ambos, recabando el cumplimiento para el Nuevo Testamento. Bajo este punto de vista se aprecia el A.T., pero sólo en la medida en que sirva para exponer el N.T. Es indudable que se observa en el Nuevo Testamento una especie de caza de tipo verbal en el amplio campo del A.T. con el fin de sorprender términos, palabras, tipos que convengan al Nuevo Testamento. Con ello se ve claro que el A.T. pierde su autonomía. Los textos son privados de su contexto original; su significación propia no es advertida ni valorada. No se ve en ellos más que la finalidad de anunciar, prefigurar la nueva economía. Es curioso observar que esta mentalidad, que comienza valorizando el A.T., termina en una desvalorización progresiva del mismo A.T.; ya que tenemos el cumplimiento, para qué se quiere la promesa; si tenemos la realidad, para qué se quiere la figura.

De otra parte, una diferente tendencia acentuará la superación de la antigua economía, la ruptura que representa la novedad del cristianismo. En esta mentalidad el A.T. se verá con aspectos negativos. Se insistirá en su aspecto caduco e imperfecto. Al final no se sabrá efectivamente para qué sirve.

Esta bipolaridad continúa a lo largo de la historia de la Iglesia. Hubo mo-

1. F. VougA, «Jésus et l'Ancien Testament»: Lumière et Vie, n. 144 (1979), 55-71. 
mentos de crisis en que el frágil equilibrio pudo romperse. Así, por ejemplo, Marción acentuó tanto la ruptura que excluyó totalmente el A.T. de las Escrituras Sagradas. La gran Iglesia no le siguió porque consideró que Marción destruía uno de los rasgos auténticos de su naturaleza: su origen judío.

De otra parte, tampoco se puede decir que los Padres de la Iglesia hicieran justicia al A.T. Principio básico de su lectura será la interpretación cristológica del A.T., siguiendo en ello la mentalidad predominante en el N.T. Los textos del A.T. serán arrancados de su contexto y privados de su espesor propio ${ }^{2}$. Como muchas veces conforme a su mentalidad, esto no será posible, se recurrirá a la alegoría y a la tipología. Puede decirse que la alegoría fue el método exegético de que se valieron para poder salvar el A.T. para el cristianismo. Esta misma postura persiste en la Edad Media con sus famosos cuatro sentidos ${ }^{3}$, influencia del platonismo.

Pero es curioso observar que en otros temas se mantiene una postura diametralmente opuesta. Si en los textos citados referentes a la cristología, el A.T. es privado de su valor propio, en la eclesiología se hará todo lo contrario. La Iglesia en la Edad Media se considera la heredera de la antigua monarquía de Israel, depositaria, por tanto, de los dos poderes, el espiritual y el temporal. Estos poderes los ejecutará nombrando y deponiendo reyes, proclamando las cruzadas, manteniendo la inquisición, etc.

En esta posición es bien visible una rejudaización del cristiànismo. Se valora al A.T. e incluso se le reconoce carácter normativo para el presente. Esto es chocante, cuando al mismo tiempo en la cristología no se quiere oír hablar de un sentido propio de los textos del A.T. ${ }^{4}$.

La época moderna introdujo en el estudio de la Biblia el método histórico-crítico, cuyo principio fundamental es la búsqueda del sentido literal, es decir, lo que el autor intentó decir con las palabras que emplea. Este método exige entender el texto en su entorno cultural e histórico. Naturalmente así entendido el A.T., la interpretación cristiana del A.T., común hasta entonces, se cuartea. Se ve claro además que el mismo N.T. cuando lee e interpreta el A.T. no se basa en criterios científicos, aceptables hoy. El método histórico-crítico consigue indudablemente darle autonomía al A.T., espesor y riqueza. Y no se ve claro cómo y de qué manera el estudio de la Biblia deba abandonar el método histórico-crítico. Precisamente por ello, se ve difícil jus-

2. Baste aludir, por ejemplo, a la «cristologización desde arriba o desde abajo» de los Salmos hecha por los Padres de la Iglesia. Véase F. VANDENBROUCKE, Los salmos y Cristo, Salamanca 1965.

3. H. de LuBAC, Exégèse Médiévale. Les quatre sens de l'Écriture. Paris, 1959-60.

4. Hablando de J.B. Bossuet hace notar este contrasentido J.L'Hour, «L'Église face à l'ancien Testament»: Lumière et Vie, n. 144 (1979) 90-93. 
tificar racionalmente la legitimidad de la interpretación cristiana del A.T. Se intenta, es verdad, articular racionalmente el sentido histórico-crítico y el sentido cristiano; pero la empresa se ve difícil, por no decir imposible, como se verá.

Nuestro intento no es analizar en general las relaciones entre el A.T. y el Nuevo. Nos limitaremos a exponer lo que el concilio Vaticano II, teórica y prácticamente, afirma sobre este delicado tema. Qué lectura del A.T. debe hacerse según el concilio, he aquí nuestra intención.

\section{Doctrina sobre el sentido literal}

La Constitución «Dei Verbum», tratando de la interpretación de la Biblia, señala el siguiente principio fundamental: «Puesto que Dios habló en la Escritura por medio de hombres y en lenguaje humano, el intérprete de la S. Escritura, para conocer lo que Dios quiso comunicarnos, debe estudiar con atención lo que los autores querían decir y Dios quería dar a conocer con las palabras de ellos» (Dei Verbum, 12).

Se adopta aquí claramente el principio de la crítica racional, el llamado sentido literal, que es el sentido de las palabras de la Escritura intentado por el autor humano. Ya Pío XII había señalado como cometido de la exégesis: «descubrir y determinar el sentido de las palabras bíblicas que llaman literal... para que aparezca la mente del autor» ${ }^{5}$. El concilio impone, pues, una lectura crítica de la Biblia, método, por otra parte, normal hoy para investigar cualquier clase de documento perteneciente al pasado.

El concilio prosigue recomendando entre otras cosas los géneros literarios, hacia los cuales adopta una posición claramente positiva. En efecto, no se recomienda la teoría de los géneros literarios con el fin de resolver dificultades contra la inerrancia como se hacía en el pasado, sino con el fin de investigar «el sentido que el hagiógrafo... quiso expresar y expresó». Se mencionan los géneros literarios y los modos de decir, porque en el pasado hubo discusión sobre su existencia y extensión, pero hay que incluir todos los demás medios que la crítica ofrece como la crítica textual, literaria, de fuentes, formal y redaccional. Es decir, se recomienda la exégesis tal como hoy se practica.

El último inciso citado de la «Dei Verbum» puede, no obstante, crear dificultades: «y Dios quería dar a conocer con palabras de ellos». Veamos el origen de este inciso. En el segundo esquema no aparecía; se limitaba a decir lo

5. «Divino Afflante Spiritu»: EB 550. 
siguiente: «quid reapse hagiographus significare intenderit». El esquema, pues, se limitaba a indicar la intención del autor ${ }^{6}$.

En el tercer esquema ya aparece la frase y el relator justifica así la adición: «Iure desiderabatur... ut praeter Hermeneuticam mere rationalem, locutio fiat etiam de principiis theologicis hermeneuticae (sensus a Deo intentus, analogia fidei, traditio). Quod factum est, in fine paragraphi. Abstrahitur autem a solvenda quaestione de sensu pleniore» ${ }^{7}$. La adición es, pues, consciente y por tanto debe significar algo que no se ha dicho en lo precedente. $\mathrm{El}$ relator indica que con esta frase se quiere sugerir que la interpretación tiene una finalidad teológica, es decir, escuchar la palabra de Dios. Por otra parte, se insiste en que el concilio ni está a favor ni en contra del sentido «plenior». En las siguientes sesiones la comisión mantendrá sủ criterio y no permitirá variar la expresión con el fin de permanecer neutral frente a las discusiones sobre el sentido «plenior» ${ }^{8}$.

Da la impresión de que el concilio buscaba la ambigüedad y ciertamente lo ha conseguido ${ }^{9}$. Dado que el concilio afirma que Dios habla por medio de hombres y en lenguaje humano, lo más lógico será pensar que sólo hay un sentido, precisamente el sentido intentado por el autor; además, el pronombre «quid» (en singular) como complemento único de las dos frases («qué quisieron los hagiógrafos significar y quiso Dios manifestar con las palabras de ellos») obliga a pensar que Dios manifiesta lo que el hombre quiere significar. Hay que insistir, pues, en el hecho de que el concilio afirma la existencia de un sentido solo; no pone fractura alguna entre dos pretendidos sentidos. La palabra divina se halla encarnada en la palabra humana (Dei Verbum, n. 13) y lo que Dios intenta comunicar se expresa en lo que intentan comunicar los autores. No existe solución de continuidad entre la intención de Dios y la de los autores sagrados.

Entonces, ¿por qué se añadió el inciso? El relator, como hemos visto, decía que con ello se quería añadir un principio teológico de interpretación y añadía entre paréntesis: sentido intentado por Dios, Tradición y analogía de la fe. Precisamente de estos principios de interpretación teológica se habla en el último párrafo del n. 12 de la Dei Verbum. En primer lugar sienta un principio: «La S. Escritura debe leerse con el mismo Espíritu con que fue escrita». Parece que se quiere decir lo siguiente: Como la Escritura es fruto de la acción

6. Acta synodalia sancrosancti concilii Oecumenici Vaticani II. Romae, 1970-80. Vol. III, Ears III,92.

7. $I b$.

8. Acta Synodalia, Vol. IV, pars I, 359; Vol. IV, pars V, 710.

9. La ambigüedad y oscuridad de la frase es reconocida por L. AlONSO-SCHÖKEL, Comentarios a la Constitución Dei Verbum sobre la divina Revelación. Madrid, 1969, 423. 
del Espíritu, como lo es también el origen de la Iglesia y demás ministerios que se ejercen en ella, el exégeta no debe olvidarse de que en su tarea no está solo, sino que su labor es también un ministerio, precisamente un servicio a la «Palabra». No con ello se abre la puerta a una exégesis salvaje o espiritual. En este caso sobrarían las recomendaciones sobre el sentido del autor humano. Lo que se pide no es abandonar la exégesis racional, o al lado de ésta añadir un «plus» de significación, sino sencillamente una docilidad al Espíritu o una simpatía o congenialidad con esa labor del Espíritu que anima a la Iglesia y de la cual él forma parte. Porque también es evidente por experiencia que la $S$. Escritura puede ser leída e interpretada sin percibir la palabra de Dios. La hermenéutica moderna pide también esta congenialidad para llegar a un auténtico comprender.

Como consecuencia de este principio, el concilio hace tres recomendaciones: «El exégeta debe atender al contenido y unidad de toda la Escritura, teniendo en cuenta la Tradición viva de la Iglesia y la analogía de la fe». Quizá en teoría sea fácil entender lo que el concilio quiere decir, pero en la labor práctica de la exégesis no se ve bien cómo estas recomendaciones se pueden llevar a cabo. No obstante, puede decirse lo siguiente: La unidad de la Escritura proviene del Espíritu, bajo cuya acción escribieron los autores como ministros de la palabra. Esta unidad proviene también de la finalidad de esta acción del Espíritu que no es otra que la revelación del misterio de Dios. Esta visión global del objeto permite percibir mejor el conjunto orgánico de la manifestación de Dios por la Escritura. Un matiz diferente se sorprende en la siguiente recomendación: «hay que atender a la Tradición». Se trata de la Tradición con letra mayúscula, en cuyo seno surgió la Escritura: es la Tradición de origen apostólico, que se expresa de modo especial en los libros inspirados (Dei Verbum, n. 8). El exégeta tiene en cuenta esta Tradición, cuando acepta la interpretación apostólica del acontecimiento de Cristo. Finalmente la analogía de la fe no parece ser otra cosa que la coherencia íntima de las diversas expresiones de la Revelación y de la fe. La analogía de la la fe ayuda al exégeta a comprender y articular mejor las diferentes expresiones de las vivencias religiosas, presentes en la Escritura.

Estas reglas de interpretación teológica están ordenadas en última instancia a averiguar lo que los autores sagrados pretendieron expresar, pues el concilio no habla de dos sentidos, sino de uno solo: el del autor humano, que es concebido como una realidad objetiva, contenida en el texto y preexistente a su lectura. Pero, para llegar a esta auténtica comprensión del texto, hay que atender al ambiente eclesial de la lectura, que ciertamente es un elemento subjetivo de la interpretación. Teóricamente el concilio no percibe que pueda haber tensión entre las dos instancias que recomienda: intención del autor y 
atención al ambiente eclesial. ¿Podrá conservarse este equilibrio en la práctica? ¿Lo mantiene el concilio en la lectura que él hace del A.T.?

\section{Doctrina sobre el Antiguo Testamento}

La Constitución «Dei Verbum» contiene un capítulo entero -el cuartodedicado al A.T. A priori, es legítimo pensar que aquí se encuentre lo que teóricamente el concilio piensa sobre el A.T., sobre su teología y sobre la relación con el N.T. Será, pues, una lectura teórica.

Tres puntos en concreto señala. En primer lugar, habla de la economía de la salvación presente ya en el A.T. Esta economía se refería a Israel, pero tenía ya en germen una proyección universal, pues en ella Dios preparaba la salvación del género humano. Se recuerdan las grandes etapas de esta historia: Abraham, Moisés, Profetas. Esta economía de la salvación se encuentra convertida en libro. Ésta es una razón para afirmar el valor perenne del A.T. Este párrafo podría considerarse como un buen resumen de la teología del A.T., en el que destaca con acierto la importancia dada a la Palabra de Dios.

Seguidamente pasa a la afirmación más importante que es la siguiente: «La economía del A.T. estaba principalmente ordenada a preparar la venida de Cristo, redentor universal y del reino mesiánico, anunciarlo proféticamente y significarlo con diversas imágenes». Si en el párrafo anterior, se admitía la autonomía del A.T., en éste esa autonomía se encuentra reducida, ya que el A.T. tenía como finalidad principal anunciar el N. T. Evidentemente lo que aquí se propone es una lectura cristiana del A.T.

A continuación el concilio señala valores positivos y negativos del A.T. en una doble frase, con conceptos e ideas que se corresponden y se repiten:

Valores positivos

Ponen a todos de manifiesto el conocimien- expresan un vivo sentido de Dios. to de Dios y de los hombres.

y los modos como Dios Justo y misericor- en los que se esconden sublimes ensedioso trata con ellos. ñanzas sobre Dios.

Demuestran la verdadera pedagogía divina. en los que está oculto el misterio de nuestra salud.

Valores negativos

Contienen cosas imperfectas y pereceras. (manifiestan el conocimiento) según la condición del género humano antes de la salud instaurada por Cristo. 
Que este párrafo es reiterativo, apologético y no muy feliz ha sido notado repetidas veces ${ }^{10}$.

Finalmente el concilio trata de las relaciones entre uno y otro Testamento (notar el singular) y lo hace citando a S. Agustín: el N. Testamento está oculto en el Viejo y el Viejo manifiesto en el Nuevo. Los libros del A.T. alcanzan su plenitud de sentido en el N.T. y, a su vez el N.T. ilumina y explica el A.T.

Leyendo el capítulo cuarto dedicado al A.T. se tiene la impresión de que el concilio quiere decir muchas cosas buenas. A nosotros nos interesan especialmente dos afirmaciones. La primera es esta: en el A.T. hay una auténtica economía de la salvación referente a Israel. En este punto no se menciona para nada a Cristo. Aquí se le reconoce autonomía al A.T. Esto corresponde efectivamente al sentido literal y es corriente en la práctica de la exégesis.

La segunda afirmación es más problemática: «el fin principalísimo de la antigua economía era preparar, anunciar y significar con varios tipos e imágenes la venida de Cristo y de su reino mesiánico». Lo que pide aquí el concilio es una lectura cristiana del A.T., lectura propagada por autores franceses ${ }^{11}$, que tanta influencia tuvieron en el concilio. Nadie niega que esta lectura cristiana es tradicional en la Iglesia desde el mismo N.T. Es común admitir que este papel asignado al A.T. por el Nuevo, y seguido luego por los Padres de la Iglesia se basa en una exégesis muy libre, en un trastorno del sentido original de los textos, inaceptable hoy día, al menos para quienes estén convencidos del método histórico-crítico. Es bien sabido que la exégesis neotestamentaria del A.T. usa muy ampliamente del sentido pleno, de alegorías, de tipologías y acomodaciones. A la mentalidad moderna le resultan caprichosas en muchos casos. Que la elevación de la serpiente en el desierto sea un símbolo de Cristo en la cruz parece tan arbitrario como ver en la matanza de los inocentes el cumplimiento de la profecía en que Jeremías presenta a Raquel llorando por los desterrados. Las citas del A.T. hechas por el Nuevo poco o nada ayudan a entender el sentido que las palabras del A.T. tuvieron para los oyentes a quienes iban dirigidos. Las referencias, pues, puntuales (relación de un texto determinado con otro del A.T.) valen muy poco y en la exégesis actual no son admitidos.

Es bastante general pensar que si la correspondencia puntual o verbal, como fue practicada por la patrística, es caduca, hoy dicha correspondencia de-

10. Ib., 522: L. Alonso-SCHÖKEL: B.D. DUPUY, La revelación divina. Constitución dogmáiica «Dei Verbum». Madrid, 1970, t. II, 76.

11. C. LARChER, L'actualité chrétienne de l'Ancien Testament, Paris 1962: P. Grelot, Sens chrétien de l'Ancien Testament, Tournai 1962. Trad. españ.: Sentido cristiano del A.T. Bilbao 1967. 
biera buscarse en los grandes contextos o en una relación tipológica de los acontecimientos del A.T. y los del N.T., o en el plano de promesacumplimiento ${ }^{12}$. Pero también esta relación es problemática. Evidentemente la antigua economía, al igual que la nueva, se manifiesta a través de los libros, en definitiva a través del lenguaje. Ahora bien, si se admite que los textos no tienen relación a nivel del lenguaje, difícilmente se puede encontrar otra relación. Por otra parte, es indudable que cualquier relación que se establezca entre el A. y el N.T. ha de echar mano de elementos que todo el mundo critica cuando lo han hecho los Padres de la Iglesia, como por ejemplo la tipología o ia alegoría.

Pero, dado el caso que la relación entre el A.T. y el Nuevo pueda hacerse (intentos hay muchos y eso prueba la debilidad de todos ellos), lo cierto es que al afirmar el concilio que el fin principalísimo del A.T. es anunciar y prefigurar el Nuevo, está apoyándose no ya en el sentido literal o histórico del A.T., sino en otro sentido que no puede ser otro que el procedente de la Tradición o del ambiente eclesial; en definitiva de un sentido que procede del lector.

El equilibrio que el concilio intentaba guardar, cuando habla del sentido de la Biblia entre la parte objetiva y subjetiva en el proceso de interpretación, aquí se rompe en favor de esta última. Se reconoce el sentido objetivo del texto del A.T., ya que se afirma que la antigua economía se refería a Israel, pero se prima el aspecto subjetivo del lector cristiano, cuando se afirma que el fin principalísimo del A.T. es anunciar a Cristo.

Esta lectura tradicional cristiana del A.T. ¿puede mantenerse? Honestamente debe uno hacerse esta pregunta. No se ve cómo la atención al texto y a la intención del autor pueda conciliarse con la interpretación cristológica del A.T. El concilio, desde luego, no se preocupó de articular estos dos sentidos. Es cosa sabida que ninguno de los textos pretendidamente cristológicos del A.T., interpretados según el sentido literal, se refieren a Cristo. Por lo mismo, una lectura cristiana necesariamente tendrá que recurrir a la tipología, alegoría, etc., elementos, que en teoría es probable que se admitan (baste citar a los teóricos del «sensus plenior»), pero que en la práctica exegética nadie ejerce. Lo que uno se pregunta, en definitiva, es si puede mantenerse este «teologoumenon» (relación entre el A.T. y N.T.), si al mismo tiempo se rechazan las técničs de interpretación que dieron vida a ese sistema de pensamiento.

12. C. WeStermanN, El Antiguo Testamento y Jesucristo. Madrid 1972, 63-70; L. Alonso-SchOKEl, Comentarios a la Constitución Dei Verbum sobre la divina Revelación. Madrid 1969, 513. Pueden verse diversos modos de resolver esta relación en el volumen colectivo de C. Westermann, Probleme alttestamentlicher Hermeneutik. Aufsätze zum Verstehen des Alten Testaments. München 1963. 
Otra pregunta conviene señalar: ¿contribuye la interpretación cristiana a una mayor inteligencia del A.T.? Es dudoso responder afirmativamente. Lo que está claro es que se priva al A.T. de espesor y autonomía. Un cristiano tenderá necesariamente a apreciarlo solamente como anunciador del Nuevo. Con lo que se expone a no valorizarlo debidamente. ¿Para qué quiere la figura si ya posee la realidad? Por otra parte se expone a reducir drásticamente los valores del A.T., porque, ¿qué papel anunciador puede sorprenderse en los diez mandamientos o en los libros sapienciales? Debido a este peligro potencial, ¿no será por lo que el concilio se sintió obligado a añadir un punto sobre los valores del A.T. en una párrafo, por lo demás, reiterativo?

\section{Uso que hace el concilio del A.T.}

En el uso práctico que hace el concilio del A.T., hay que resaltar, ante todo, la sobriedad. Únicamente se cita el A.T. 87 veces, de las cuales 18 son citas explícitas. El resto son referencias en el texto o a pie de página. Si se tiene en cuenta que el N.T. es citado unas 1300 veces, no se puede por menos de notar lo comedido que ha sido el concilio respecto del A.T.

Más concretamente, debemos decir que el concilio usa bien el A.T. cuando habla del hombre en general, es decir, cuando toca temas de antropología religiosa. Algunas veces, incluso resulta moderno. Así expone el concilio que, según la revelación, el hombre creado a imagen de Dios, fue constituido señor para gobernar y usar del mundo (Const. sobre la Iglesia en el mundo actual, 12,34 , que cita a Gén 1 y Sab 2,$23 ; 9,3$ ); el estado social del hombre se fundamenta en la creación del hombre y de la mujer (Const. sobre la Iglesia en el mundo actual, 12,50, que cita a Gén 1,27 y 2,18); el carácter fecundo del hombre encuentra su confirmación en el mandato «creced y multiplicaos» (Const. sobre la Iglesia en el mundo actual, $50=$ Gén 1,28). El hombre es libre (Const. sobre la Iglesia en el mundo actual, $17=$ Eccli 15,14 ), dueño de toda la creación (Const. sobre la Iglesia en el mundo actual, 12,34= Sal 8,5-7). Cuando el hombre trabaja sigue el plan divino de la creación, según el cual el hombre debe someter la tierra (Const. sobre la Iglesia en el mundo actual, 57= Gén 1,28); el hombre por la fe puede contemplar y saborear el misterio del plan divino sobre el mundo (Const. sobre la Iglesia en el mundo actual, 15=Eccli 17,7-8). Que el hombre aspire a la paz no es algo exclusivamente moderno. Y le resulta fácil al concilio encontrar textos en el A.T. (Const. sobre la Iglesia en el mundo actual, $78=$ Is 2,4 ).

Cuando el concilio hace afirmaciones genéricas acerca de Dios y el mundo también recurre al A.T. y su uso es correcto. Así habla de la presencia de Dios y su providencia que abarca a todos (Const. sobre la Iglesia en el mundo 
actual, 57; Decr. sobre las religiones no cristianas, 1 que citan a Prov 8,30-31; Sab 8,1); tan presente está Dios en el mundo que penetra en lo más íntimo del hombre (Const. sobre la Iglesia en el mundo actual, $14=1 \operatorname{Re} 16,7^{13}$; Jer 17,10). Dios es bueno; no quiere la muerte. La muerte corporal entró en la historia a consecuencia del pecado (Const. sobre la Iglesia en el mundo actual, $18=$ Sab 1,$\left.13 ; 2,23-24{ }^{14}\right)$. Esta bondad es extensiva al mundo. Las cosas naturales están bien hechas (Decr. sobre el apostolado de los seglares, 7; Const. sobre la Iglesia en el mundo actual $12=$ Gén 1,31 ${ }^{15}$ ).

Más interesante aún resulta que el concilio se dirija a los casados y a los novios con estas palabras: «Muchas veces a los novios y a los casados les invita la palabra divina a que alimenten y fomenten el noviazgo con un casto afecto y el matrimonio con un amor único» (Const. sobre la Iglesia en el mundo actual, 49). Y en apoyo de tal doctrina se cita a Gén 2,22-24; Prov. 5,15-20; 31,10-31; Tob 8,4-8; Cant 1,2-3.16; 4,16-5,11; 7,8-14. Es notable que se cite en este contexto el Cantar de los Cantares, pues es tradicional entenderlo del amor de Yahvé a su pueblo o aplicarlo a Cristo y a su Iglesia o incluso al alma humana. Que el concilio los cite hablando del amor humano resulta moderno.

Todas estas citas que hemos recorrido tienen un alcance universal. De ahí que no sea necesaria ninguna transposición ni recurrir a la tipología o alegoría para aplicarlos al hombre de hoy.

Más dificultades ofrece la lectura que hace el concilio en contextos cristológicos o eclesiológicos.

Sintomático es ya el uso que hace de Jer 31,31-34. Después de mencionar el pacto que Dios hizo con Israel, prosigue: «Pero todo esto lo realizó como preparación y símbolo del pacto, nuevo y perfecto, que había de efectuarse en Cristo, y de la plena revelación que había de hacer por el mismo Verbo de Dios hecho carne». Copia el concilio el texto de Jer 31,31-34. Seguidamente

13. Es curioso que se cite este texto como 1 Re 16,7 , dando a entender que se ha usado la Vulgata. Es más usual 1 Sam 16,7, nomenclatura que el concilio en otras partes emplea.

14. Aquí hubiese sido necesario más rigor. El libro de la Sabiduría habla de la muerte escatológica, y no simplemente de la muerte física o corporal.

15. En el Decr. sobre el Apostolado de los seglares hay un párrafo un tanto extri i :: «Todo lo que constituye el orden temporal: bienes de la vida y de la familia, la cultura, la ec : imía, las artes y las profesiones, las instituciones de la comunidad política, las relaciones intern ${ }_{2} \cdot$ onales y otras realidades semejantes, así como su evolución y progreso, no son solamente medio para el fin último del hombre, sino que tienen, además, un valor propio puesto por Dios en ellos, ya se les considere en sí mismos, ya como parte de todo el orden temporal: $\mathrm{Y}$ vio Dios todo lo que había hecho y era muy bueno (Gén 1,31)» (n. 7). No sé si todas las cosas que el concilio enumera en esta lista pueden ser consideradas muy buenas, pero ciertamente la afirmación de Gén 1,31 no recubre ni ampara la lista anterior. 
añade: «El tal pacto nuevo lo estableció Cristo, a saber el N.T. en su sangre» (Luz de las gentes, 9).

Es verdad que se admite distinción entre la antigua y nueva alianza. Pero las palabras de Jeremías son aplicadas directamente a Cristo, como si el profeta se estuviera refiriendo a la alianza concluida por Jesús en el N.T. La recomendación hecha en la «Dei Verbum» de investigar lo que el autor quería decir, no parece preocupar mucho en este momento.

La misma actitud mental aparece en temas cristológicos y mariológicos. Así tranquilamente afirma el concilio: «Estos primeros documentos (los libros del A.T.), tal como son leídos en la Iglesia y son entendidos bajo la luz de una ulterior y más plena revelación, iluminan cada vez con mayor claridad la figura de la mujer, Madre del Redentor; ella misma, bajo esta luz, aparece delineada proféticamente en la promesa de victoria sobre la serpiente, dada a nuestros primeros padres caídos en pecado (Gén 3,15). Así también, ella es la Virgen que concebirá y dará a luz un Hijo, cuyo nombre será Emmanuel (Cfr. Is 7,14; Miq 5,2-3; Mt 1,22-23» (Luz de las gentes, 55).

En esta cita se ve bien la ambigüedad en la que se mueve el concilio respecto del A.T. Se nota en el inciso que se intercala: «Estos textos, tal como son leídos en la Iglesia y son entendidos bajo la luz de una ulterior y más plena revelación». Esto parece dar a entender que el concilio es consciente de que los textos indicados leídos en sí mismos, no soportarían tal interpretación. Es preciso notar que el relator de la comisión que preparaba el esquema se ve obligado a decir: «sed expresse notatur quod libri inspirati in Ecclesia Catholica, sicut oportet, sub lumine plenae revelationis leguntur et secundum mentem Traditionis intelliguntur» ${ }^{16}$. La verdad es que estas palabras del relator no son muy felices. Porque, ¿para qué insistir en la «Dei Verbum» sobre el sentido intentado por el autor, si al final lo que prima es el sentido que la Iglesia le da? Lo que extraña es que teóricamente se predique una cosa y en la práctica, por seguir la tradición, se haga otra cosa. La advertencia del cardenal Bea de que no se citase Gén 3,15 , por ser un texto discutido, no sirvió para nada ${ }^{17}$. Al texto de Gén 3,15 vuelve a hacer el Concilio otra referencia: «Y después de su caída (la de los primeros padres) los levantó a la esperanza de salvación por la promesa de la redención (Dei Verbum, 3). Incluso esta interpretación, que puede llamarse tradicional, bajo el punto de vista exegético, deja mucho que desear. Porque en el texto no se habla de victoria alguna, sino en todo caso de lucha continua.

16. Acta Synodalia, Vol. III, pars I,367.

17. Acta Synodalia, Vol., III, pars I,455. 
Dadas estas lecturas, no es extraño que el concilio aplique a Cristo textos que según el sentido literal, no se pueden hacer. «Las naciones - afirmahan sido dadas a Cristo en herencia» (Luz de las gentes, $13=$ Sal 2,8); como si Cristo se identificara con el Rey de Israel. Lo sorprendente es que no se perciba ni siquiera la distancia. A la ciudad de este gran rey, identificado con Cristo «llevan (las naciones) dones y presentes» (Luz de las gentes, $13=$ Sal 72,10; Is 60,4-7). Esta aplicación resulta ciertamente chocante.

Sucede lo mismo, si pasamos a otro tema: la Iglesia. Así se afirma de ella que «es una grey, cuyo pastor es el mismo Dios, según las profecías (Is 40,11; Ez 34,11ss)», (Luz de las gentes, 6). Debe notarse el carácter profético que se le concede a estos textos. Parece que la única finalidad reconocida es anunciar la naturaleza de la Iglesia. «La Iglesia es también la viña del Señor (Is $5,1 \mathrm{ss}$ ) plantada por el celestial agricultor (Luz de las gentes,6)». A la Iglesia «pueblo de Dios se dijo de manera profética: 'amplía el lugar de tu tienda y extiende las pieles que te cubren. No te cohibas' (Is 54,2)» (Luz de las gentes, 9). Como se ve, no se percibe alteridad alguna. Si en los textos anteriores se aplicaban a la Iglesia frases dichas del pueblo de Israel, no es extraño que se aplique a ella lo que en el A.T. se atribuye a la dinastía de David. La Iglesia es «signo levantado ante las naciones (Is 11,12$) »$. Texto que parece gozar de cierta predilección por el concilio, pues es citado tres veces: Const. sobre Sagrada liturgia, 2; Decr. sobre Ecumenismo, 2; Decr. sobre la actividad misionera de la Iglesia, 36.

Siguiendo esta misma mentalidad, el concilio no tiene reparo alguno en citar el texto de Mal 1,11, cuando habla de la Eucaristía. El sacerdote «realiza (adimplet) las palabras de Dios dichas por el profeta: desde la salida del sol hasta su ocaso es grande mi nombre entre las gentes y en todo lugar se ofrece a mi nombre una oblación pura» (Luz de las gentes, 17). Que la Eucaristía sea el cumplimiento de las palabras de Malaquías, nadie hoy puede mantenerlo si se quiere atender al sentido literal y a la intención del autor, como el mismo concilio en teoría exige.

Más curioso es que se aplique a los sacerdotes de hoy palabras dirigidas a los sacerdotes del A.T., no explicando qué relación puede haber entre ambas instituciones, si es que puede haber alguna. Así se dice a los sacerdotes que «su parte y herencia es el Señor (Núm 18,20)» (Decr. sobre los presbíteros, 17). Esta frase puede ser muy bonita, pero ciertamente no es el sentido que el autor sacerdotal del A.T. quería indicar con estas palabras. No se percibe ruptura entre el sacerdote del A.T. y del Nuevo. Y es por ello por lo que el concilio dice que «es lícito de todo punto requerir la palabra de Dios de la boca de los sacerdotes». Aquí cita indistintamente Mal 2,7; 1 Tim 4,11-13; 2 Tim 4,5; Tit 1,9. Ve también a los sacerdotes poseídos por el Espíritu como los setenta va- 
rones sobre quienes vino el espíritu de Moisés (Núm 11,16-25; Decr. sobre los presbíteros, 7). Si lo que se quiere decir es que los presbíteros tienen o deben tener una dimensión profética, peor ejemplo en el A.T. no se puede encontrar, porque no parece que los sacerdotes tengan trances proféticos, como es el profetismo de los setenta varones citados. De igual manera procede el concilio cuando deduce de $\mathrm{Ez}$ 34,14 que es deber de la Jerarquía «apacentar al pueblo de Dios y conducirlo a pastos mejores» (Luz de las gentes 45).

En muchos casos citados se trata de acomodaciones o de ejemplos típicos o textos ejemplares que se eligen con el fin de ilustrar una verdad. Es decir, se trata de un uso tan libre de la Escritura que el Concilio no está lejos de la Carta a los Hebreos; y, a propósito, hay un ejemplo que confirma esta impresión. Hablando del sacerdocio de Cristo, afirma: «El sacerdocio de Cristo, del que los presbíteros han sido hechos partícipes se dirige necesariamente a todos los pueblos y a todos los tiempos, como misteriosamente se representa ya en la figura de Melquisedec» (Decr. sobre los presbíteros, 10). Y naturalmente se cita a Hebr 7,3. Tan misteriosamente está representado el sacerdocio cristiano por la figura de Melquisedec, que no puede saberse qué relación puede haber entre ambos, por más tradicional que sea esta comparación. No puede considerarse muy moderno el concilio usando esta tipología.

En el uso práctico del A.T. el concilio Vaticano II es menos moderno de lo , ue a primera vista pudiera parecer. Desde luego, resulta extraño que, mientras en la «Dei Verbum», es decir, en teoría, se acentúe el carácter objetivo del sentido, en la práctica se olvida de la teoría y se recurre a una subjetividad tan tradicional como cuando no se había aún descubierto lo que es el sentido literal. Hay una marcada apropiación del A.T. sin respeto alguno al texto, que en teoría se había recomendado. La hermenéutica tiene, no cabe duda, una dimensión objetiva y subjetiva. En la «Dei Verbum» se había intentado guardar el equilibrio. En la práctica, en cambio, la lectura subjetiva suplanta cualquier otra consideración.

Tampoco el concilio se preocupó de articular el sentido cristiano que en la práctica usa con el sentido intentado por el autor que en teoría exige. El concilio, pues, no resuelve las dificultades que la lectura del A.T. ha ocasionado a lo largo de la historia de la Iglesia.

Nuestro intento ha sido sencillamente exponer la contradicción existente en el concilio entre la teoría y la práctica en la interpretación del A.T. No hemos querido tocar el tema de la relación entre el A.T. y el Nuevo, tema por lo demás complicado y que el concilio no resuelve. Nos parece, no obstante, que la lectura cristiana del A.T. encontrará siempre dificultades imposibles de superar. Esta lectura recurrirá siempre a métodos que todo el mundo reprocha cuando los ejercitan los Padres de la Iglesia. 
Por otra parte, la lectura cristiana del A.T. no consigue revalorizar el A.T. de una manera adecuada. Es curioso, por ejemplo, el caso del libro del profeta Amós. La crítica social, que es el mensaje casi único del libro, no jugó ningún papel en la historia de la interpretación cristiana. En cambio sí es comentado muchas veces el texto de Am 9,11-15 sobre la restauración de la dinastía de David, y solamente porque se veía su cumplimiento en Jesucristo ${ }^{18}$. Este texto en el libro de Amós es un apéndice y, según el parecer común, una adición. Éste es un caso claro en que la interpretación crítica consigue revalorizar mejor un libro del A.T. que la lectura cristiana. Estos ejemplos podrían multiplicarse. Con el libro de Miqueas, sucede lo mismo. El texto de Miq 5,1-5 sobre el nacimiento en Belén del futuro dominador de Israel ha tenido más importancia que la crítica social que hace.

Creemos que el mejor modo de valorizar el A.T. sería, no la lectura cristiana, sino la crítica. En la primitiva comunidad cristiana, el A.T. fue la única Escritura que existía. Más tarde a la Escritura del A.T. se le sumó el N.T. Pero, mientras tanto, el A.T. era tenido por norma de vida en aquellas cosas en que su autoridad no había sido suplantada por la del Kyrios. Hoy también sería mejor leer el A.T. apreciando los valores que tiene, reconociendo su valor normativo, en aquellas cosas en que su autoridad no ha sido descalificada por el N.T. ¿No es así, como la teología de la liberación o de la esperanza (Moltmann) ha conseguido percibir el valor de muchos textos del A.T., que antes no eran apreciados?

\section{Mielgo} 485 .

18. L. MARKeRT, «Amós»: Theologische Realenzyklopaddie, Berlin-New York 1978, 2, 484- 